\title{
Intraosseous lidocaine provides effective analgesia for percutaneous vertebroplasty of osteoporotic fractures
}

\author{
[L'administration intra-osseuse de lidocaïne procure une analgésie efficace \\ pendant la vertébroplastie percutanée de fractures ostéoporotiques]
}

Musa Sesay MD, ${ }^{*}$ Vincent Dousset MD PhD,$\dagger$ Dominique Liguoro MD PhD, $\ddagger$ Fabienne Péhourcq MD, $\mathbb{S}$ Jean- Marie Caillé MD, $†$ Pierre Maurette $\mathrm{MD}^{*}$

Purpose: To assess the safety and efficacy of intraosseous lidocaine (IL), in comparison with iv nalbuphine and propacetamol (NP) for analgesia during percutaneous vertebroplasty (PV) in order to avoid general anesthesia in elderly patients.

Methods: Patients (age $68 \pm 13$ yr, weight $66 \pm 6 \mathrm{~kg}$ ) undergoing $\mathrm{PV}$ for osteoporotic fractures were randomized prospectively into two groups: NP $(n=50)$ and IL $(n=50)$. All patients were premedicated (oral hydroxyzine I $\mathrm{mg} \cdot \mathrm{kg}^{-1}$ ) and had skin infiltration with $5 \mathrm{~mL}$ of $1 \%$ lidocaine prior to vertebral puncture. Thirty minutes before the procedure, Group NP received, in a blinded manner, $50 \mathrm{~mL}$ of iv nalbuphine $\left(0.3 \mathrm{mg} \cdot \mathrm{kg}^{-1}\right)$ and propacetamol (30 $\mathrm{mg} \cdot \mathrm{kg}^{-1}$ ) while Group IL received $50 \mathrm{~mL}$ of iv saline. During vertebral puncture, Groups NP and IL received, in a blinded manner, I $\mathrm{mL} \cdot 10 \mathrm{~kg}^{-1}$ of intraosseous saline and $1 \%$ lidocaine respectively. Pain was assessed during vertebral puncture and cement injection with a four-point verbal rating scale. Additionally, lidocaine plasma kinetics were obtained in I I IL patients.

Results: Analgesic efficacy was similar in the IL and NP groups (85 vs 84\%). Group NP had more side effects. Lidocaine peak recorded concentration was $2.6 \pm 0.1 \mu \mathrm{g} \cdot \mathrm{mL}^{-1}$ i.e., about three times less than the reported toxic limits.

Conclusion: IL is as effective as the association of iv NP for analgesia in PV. However, considering that both protocols were insuffcient in about $15 \%$ of cases, other modalities are needed to further improve analgesia and avoid general anesthesia during vertebroplasty.
Objectif : Évaluer l'efficacité et la sécurité d'une injection intraosseuse de lidocaïne (IL) comparée à une sédation iv à base de nalbuphine et de propacétamol (NP) pour l'analgésie des vertébroplasties percutanées (VP) afin d'éviter l'anesthésie générale chez des patients âgés.

Méthode : Cent patients devant subir une VP sont prospectivement randomisés en deux groupes : 30 min avant la procédure, le groupe $N P$ reçoit en aveugle $50 \mathrm{~mL}$ d'un mélange iv de nalbuphine $(0,3$ $\left.\mathrm{mg} \cdot \mathrm{kg}^{-1}\right)$ et de propacétamol $\left(30 \mathrm{mg} \cdot \mathrm{kg}^{-1}\right)$ tandis que le groupe IL reçoit $50 \mathrm{~mL}$ iv de solution salée. Tous les patients reçoivent une prémédication avec de l'hydroxyzine ( $\left.\mathrm{l} \mathrm{mg} \cdot \mathrm{kg}^{-1}\right)$ et ont une infiltration cutanée avant la ponction vertébrale avec $5 \mathrm{~mL}$ de lidocaïne $1 \%$. Pendant la ponction vertébrale, le groupe NP reçoit à son tour une solution salée alors que le groupe $1 \mathrm{~L}$ reçoit $1 \mathrm{~mL} \cdot 10 \mathrm{~kg}^{-1}$ de lidocaïne I \%. La douleur est évaluée pendant l'opération par une échelle verbale à quatre degrés. Un profil cinétique de la lidocaïne plasmatique est réalisé chez les II premiers patients.

Résultats : Une analgésie efficace est constatée dans les groupes IL et NP dans 85 et $84 \%$ des cas respectivement. Le groupe NP présente plus d'effets secondaires. Le pic plasmatique de lidocaïne circulante est 2,6 $\pm 0,1 \mu \mathrm{g} \cdot \mathrm{mL}^{-1}$ soit trois fois moins que les limites toxiques.

Conclusion : La lidocaïne intra-osseuse procure la même analgésie que l'association iv de NP pour les VP. Étant donné que les deux protocoles sont insuffisants dans environ $15 \%$ des cas, d'autres associations sont nécessaires pour améliorer encore l'analgésie et éviter l'anesthésie générale.

From the Department d'Anesthésie-Réanimation $3,{ }^{*}$ Service de neuroradiologie diagnostique et thérapeutique, $\dagger$ Service de neurochirurgie A, $\ddagger$ Service de pharmacologie clinique et toxicologie $\$$

Centre Hospitalier Universitaire Pellegrin, Bordeaux Cedex, France.

Address correspondence to: Dr. Pierre Maurette, Département d'Anesthésie-Réanimation 3 Centre Hospitalier Universitaire Pellegrin, 33076 Bordeaux Cedex, France. Phone: 33-5-56 79-55-15; Fax: 33-5-56 79-61-19; E-mail: pierre.maurette@chu-bordeaux.fr Accepted for publication September 10, 2001.

Revision accepted November 15, 2001. 
$\mathrm{P}$ ERCUTANEOUS vertebroplasty (PV) is a new technique designed to consolidate pathologic vertebral bodies through the injection of orthopedic cement (methylmethacrylate) under fluoroscopic guidance. ${ }^{1,2}$ Consolidation provides rapid pain relief to most lytic and painful vertebral body lesions secondary to osteoporosis, hemangiomas and metastatic diseases. ${ }^{3}$ The procedure is short (about one hour) but painful during vertebral puncture and cement injection. ${ }^{2}$ The duration of each of these painful moments of PV is about five minutes. Different anesthetic techniques have been proposed to control pain during vertebroplasty, but all have important limitations. On the one hand, general anesthesia adds its own risks ${ }^{4}$ and prevents clinical assessment of the patient during the procedure. Sedative analgesia with opioids and benzodiazepines, which is currently the main analgesic technique for $\mathrm{PV},{ }^{2}$ can be hazardous, specially with the patient in the prone position, as conventional systemic opioid administration entails the potential risk of respiratory depression. The rationale behind the intraosseous injection of a local anesthetic involves a regional blockade of the bone nociceptive fibres, thereby avoiding the major complications of sedation or general anesthesia. In 1947, Orlov performed the first intraosseous anesthesia with lidocaine on a patient's arm after excluding the systemic circulation by a tourniquet. ${ }^{5}$ This technique has since been validated by others. ${ }^{6}$ However, in the case of intravertebral injection, complete exclusion of the systemic circulation is impossible and consequently, toxicity of the local anesthetic becomes an important concern.

The present study was undertaken to assess both the safety and efficacy of analgesia with intraosseous lidocaine (IL), compared to iv nalbuphine associated with propacetamol, for PV of osteoporotic fractures.

Methods

\section{Patient selection}

After Institutional Review Board approval and informed consent, 100 ASA physical status I-III patients scheduled to undergo PV for osteoporotic vertebral compression fractures (VCF) were included in this prospective study. The fractures were associated with age-related osteopenia in 85 patients and steroid-induced in the 15 others. Diagnostic criteria for inclusion were: (1) patients suffering from back pain and refractory to a four-week medical treatment (bed rest, analgesics and bracing); (2) physical examination confirming VCF pain which is usually localized to the area of fracture, worsens with weightbearing and improves when the patient lies down; (3) mag- netic resonance imaging (MRI) or unenhanced computed tomography scan showing vertebral body collapse and continuity of the posterior vertebral wall. Additionally, an acute VCF can be identified on Tlweighted sagittal sequence of MRI by a low (dark) signal of the vertebral body. The decision to perform a vertebroplasty was made by a multidisciplinary team including a neuroradiologist, a rheumatologist, an orthopedist, a neurosurgeon, and an anesthesiologist. The procedure was discussed with the patients and the potential benefits and risks outlined. The potential complications specified were bleeding at the puncture site, bone infection, diffusion of cement to soft tissues, spinal canal or veins with the risk of neural damage and pulmonary embolism. The thoracic region approach presents an additional risk of pneumothorax. The patients were also informed of the possibility of emergency decompressive surgery in case of important leakage of cement. Patients with coagulation disorders or allergic to any of the drugs used in the study and those with severe renal, hepatic and cardiorespiratory diseases were excluded.

\section{Analgesic protocols and trocar insertion}

The patients were randomly allocated to one of the two groups: IL (Group IL, $n=50$ ) and $i v$ nalbuphine associated with propacetamol (Group NP, $n=50$ ). Randomization was done at the department of pharmacology by drawing lots composed of 100 inscriptions (50 of each group) sealed in untitled envelops. The drugs were prepared by the same pharmacologist who was informed only of the patient's weight. With the exception of the first 11 lidocaine patients who had plasma lidocaine measurements, the patient, anesthesiologist and neuroradiologist were blinded to the $i v$ and intraosseous solutions used. One hour before the procedure, each patient was premedicated with oral hydroxyzine $\left(1 \mathrm{mg} \cdot \mathrm{kg}^{-1}\right)$. On arrival at the radiology unit, a 18-gauge cannula was placed in a peripheral arm vein for fluid and drug infusion. The procedure was performed in a strictly sterile manner. The patients were placed in a prone position with a cushion under the abdomen and breathing room air. Thirty minutes before the injection of cement, group NP received, in a blinded manner, an infusion of 50 $\mathrm{mL}$ of nalbuphine $\left(0.3 \mathrm{mg} \cdot \mathrm{kg}^{-1}\right)$ associated with propacetamol $\left(30 \mathrm{mg} \cdot \mathrm{kg}^{-1}\right)$ over ten minutes while group IL received saline intravenously. The intraosseous injections, concomitant with trocar insertion, were carried out by a senior neuroradiologist (four participated in this study). First, local anesthesia of the trocar insertion tract (from skin to periosteum) was performed with $5 \mathrm{~mL}$ of $1 \%$ lidocaine using a 21 - 
gauge needle. Then a $3-\mathrm{mm}$-diameter, $10-\mathrm{cm}$ long trocar (Escoffier ${ }^{\mathrm{TM}}$, Thonon Les Bains, France) was introduced up to the level of the periosteum. A transpedicular route was selected for vertebral body puncture using progressive rotating movements of the trocar. Each progression of the trocar was accompanied by the injection, in a blinded manner, of 1 to 2 $\mathrm{mL}$ of a solution containing $1 \mathrm{~mL} \cdot 10 \mathrm{~kg}^{-1}$ of either $1 \%$ lidocaine (group IL) or saline (group NP) until final placement in the middle of the vertebral body. All patients received the full dose of the solution without flushing considering the small dead space of the trocar shaft $(0.5 \mathrm{~mL})$.

\section{Cement injection and monitoring}

The trocar was left in place after intraosseous injection of the local anesthetic. Then, the cement mixture (Antibiotic Howmedica, Shannon Co. clair, Republic of Ireland) was prepared with $20 \mathrm{~mL}$ of methylmethacrylate powder, $5 \mathrm{~mL}$ of liquid methylmethacrylate and $1 \mathrm{~g}$ of radiopaque tungsten powder. When the mixture had the viscosity of toothpaste (i.e., about five minutes later), 3 to $10 \mathrm{~mL}$ were injected through the trocar using luerlock syringes. The procedure was performed under fluoroscopic guidance with real time imaging during injection of cement to determine the degree of vertebral filling and to detect possible cement leaks. The injection was stopped when the cement reached the posterior vertebral wall or whenever it diffused outside the vertebral body. Cement injection was also stopped immediately if the patients complained of radicular symptoms. Blood pressure, heart rate (HR) and pulse oximetry were monitored throughout the procedure (Eagle $3000^{\mathrm{TM}}$, Marquette medical systems, Milwaukee, USA). Adverse effects and their appropriate management were noted.

\section{Assessment of pain and patient satisfaction}

Pain was assessed by means of a four-point verbal rating scale (VRS) adapted from Keele's pain chart ${ }^{7}$ [ $0=$ no pain, $1=$ mild pain, $2=$ moderate pain, $3=$ severe pain]. The scores were obtained at four different phases: baseline, trocar insertion, trocar in correct position, and finally during cement injection. Repeated measures were performed at each phase and the highest pain score was retained. Analgesic efficacy was defined by a VRS $<2$. Patients with severe pain during trocar insertion or cement injection received sedation with propofol $\left(0.5 \mathrm{mg} \cdot \mathrm{kg}^{-1}\right)$ in order to prevent unintentional movement. Patient satisfaction was assessed upon leaving the recovery room by a staff nurse, using a satisfaction score (excellent $=4$, very $\operatorname{good}=3$, $\operatorname{good}=2$, fair $=1$ or poor $=0$ ). The nurse also noted the reasons of dissatisfaction: inadequate pain relief, nausea, vomiting, pruritis, headache, numbness, restlessness, somnolence, blurred vision or any other complaint.

\section{Lidocaine plasma levels}

Intraosseous injections of lidocaine were not blinded in the first 11 patients in order to measure lidocaine plasma levels. Following intraosseous injection, venous blood samples of $3 \mathrm{~mL}$ were drawn in heparinized tubes at five, ten, 20,30, 40 and $60 \mathrm{~min}$ in each of the 11 patients. Samples were kept vertically, in ice, until centrifugation, and plasma was kept frozen at $-70^{\circ} \mathrm{C}$ until analysis. Plasma lidocaine concentrations were measured using enzyme multiple immunoassay technique (EMIT $®$ Syva Lab Processor 6000 Series, San Jose, CA, USA). Plasma lidocaine levels are expressed as $\mu \mathrm{g} \cdot \mathrm{mL}^{-1}$ and the limit of detection was $0.09 \mu \mathrm{g} \cdot \mathrm{mL}^{-1}$.

\section{Statistical analysis}

Age and weight were analyzed by unpaired tests. Hemodynamic parameters were compared by repeated measures of analysis of variance followed by Tukey post hoc test. Analgesic efficacy and patient satisfaction were compared by Chi-square or Fischer's exact test where appropriate. For all comparisons, a $P$ value $<0.05$ was considered significant.

\section{Results \\ Clinical outcomes}

There were no significant differences between the two treatment groups with respect to age, weight and duration of the procedure (Table I). Analgesic profiles of the IL and NP groups were similar (Table II). Both techniques provided satisfactory pain relief during trocar insertion and cement injection. Severe pain requiring propofol sedation was observed in five IL patients and six in the NP group specially during trocar insertion. Two patients in the IL group had bradycardia (42 and 44 beats. $\mathrm{min}^{-1}$; baseline 75 and 79 beats. $\mathrm{min}^{-1}$ respectively) immediately after injection of lidocaine and were managed by $0.5 \mathrm{mg}$ of $i v$ atropine in each case. In the NP group, four patients with nausea and one with vomiting required the $i v$ injection of metoclopramide 10 $\mathrm{mg}$. After installation in the prone position, two NP patients developed desaturation $\left(\mathrm{SpO}_{2} 90 \%\right.$ and $91 \%$; baseline $98 \%$ each) for more than two minutes, warranting oxygen administration $\left(6-10 \mathrm{~L} \cdot \mathrm{min}^{-1}\right)$ via a face mask. During the injection of cement, slight modifications of mean arterial pressure and HR were observed in the two groups. These changes were transient 
TABLE I Demographic and analgesic profiles of the two treatment groups

\begin{tabular}{|c|c|c|}
\hline & $\begin{array}{l}I L \\
(n=50)\end{array}$ & $\begin{array}{l}N P \\
(n=50)\end{array}$ \\
\hline Age (yr) & $68 \pm 12$ & $67 \pm 13$ \\
\hline Sex: male/female $(n)$ & $23 / 27$ & $21 / 29$ \\
\hline Weight (kg) & $66 \pm 6$ & $66 \pm 5$ \\
\hline ASA physical status: I/II/III $(n)$ & $0 / 21 / 29$ & $2 / 22 / 26$ \\
\hline Duration of vertebroplasty ( $\mathrm{min}$ ) & $60 \pm 15$ & $62 \pm 15$ \\
\hline $\begin{array}{l}\text { Vertebral body concerned: } \\
\text { thoracic/lumbar }(n)\end{array}$ & $26 / 24$ & $28 / 22$ \\
\hline Quantity of cement injected (mL) & $5 \pm 1.5$ & $4 \pm 1.3$ \\
\hline $\begin{array}{l}\text { Propofol used to prevent unintentional } \\
\text { movements }(\mathrm{mg})\end{array}$ & $33.3 \pm 1.4$ & $32.0 \pm 3.0$ \\
\hline
\end{tabular}

No statistically significant difference between groups.

$\mathrm{IL}=$ intraosseous lidocaine; $\mathrm{NP}=$ nalbuphine and propacetamol.

TABLE II Pain assessment during percutaneous vertebroplasty

\begin{tabular}{llllll}
\hline \multirow{2}{*}{ Period } & & \multicolumn{4}{c}{ Verbal rating scale } \\
& Group & $O(n)$ & $1(n)$ & $2(n)$ & $3(n)$ \\
\hline Baseline & I L & 48 & 2 & 0 & 0 \\
\multirow{5}{*}{ Trocar insertion } & NP & 49 & 1 & 0 & 0 \\
& I L & 23 & 18 & 5 & 4 \\
Trocar in place & NP & 20 & 25 & 2 & 3 \\
& I L & 43 & 4 & 3 & 0 \\
Cement injection & NP & 42 & 5 & 3 & 0 \\
& I L & 38 & 5 & 6 & 1 \\
& NP & 27 & 13 & 7 & 3 \\
\hline
\end{tabular}

Pain was assessed by means of a four-point verbal rating scale: $0=$ no pain, $1=$ mild pain, $2=$ moderate pain, $3=$ severe pain. No statistically significant difference between groups. IL=intraosseous lidocaine; $\mathrm{NP}=$ nalbuphine and propacetamol.

(Figure 1). Overall patient satisfaction rates were 90\% and $86 \%$ in groups IL and NP respectively (Figure 2). Dissatisfaction with the analgesic techniques were qualified by the terms: painful (one patient in group IL, one in group NP), vomiting (one patient in group NP) and somnolence (two patients in group NP). Discomfort in the prone position was expressed by the remainder of the unsatisfied patients.

Vertebral fracture pain subsided within the first hour after vertebroplasty in $95 \%$ of the patients with improved mobility the next day. However, in $5 \%$ of the patients, only moderate pain relief was observed within $24 \mathrm{hr}$. A few incidents associated with vertebroplasty were observed: diffusion of cement to the intervertebral disc $(n=2)$, spinal canal $(n=1)$ and paravertebral veins $(n=3)$. However the patients remained asymptomatic on postoperative follow- up. Recurrent fractures involving the adjacent vertebral bodies (not initially detected) were observed in $12 \%$ of patients

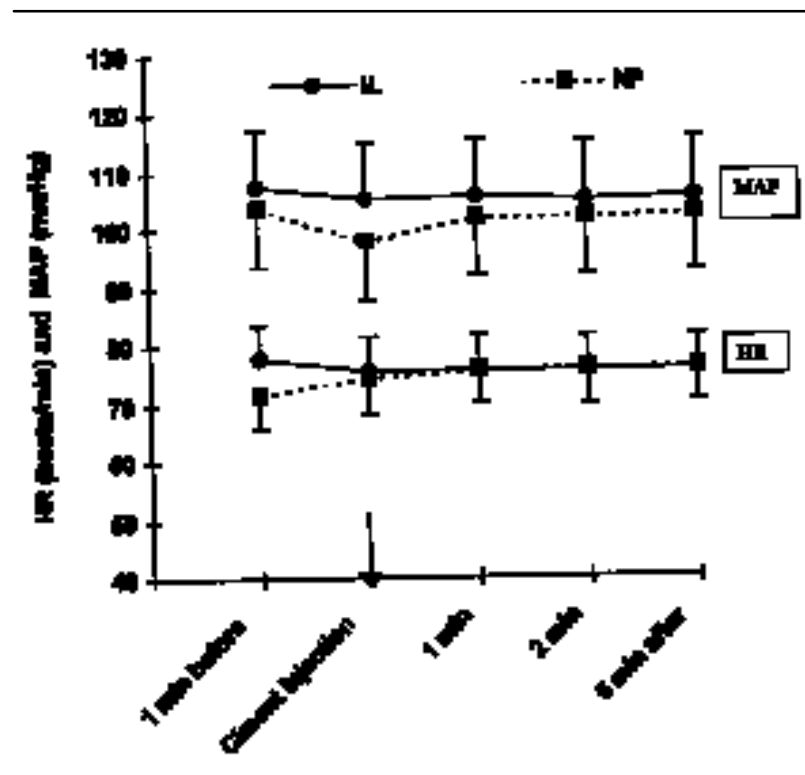

FIGURE I Cardiovascular changes during percutaneous vertebroplasty with cement injection into the vertebral body. The changes were not statiscally significant. Data are presented as mean \pm SD.

within three months of vertebroplasty, specially in patients who had persistent pain. A new procedure was performed in these patients without including them in the protocol.

\section{Lidocaine plasma concentrations}

Complete data on lidocaine plasma levels were obtained in a subset of 11 patients in the IL group. The mean dose of lidocaine used in these patients was $125 \pm 10 \mathrm{mg}$. This included the $50 \mathrm{mg}$ lidocaine used for skin and periosteal infiltration. Two pharmacokinetic profiles were present (Figure 3). A Tmax for lidocaine concentration $\left(2.0 \pm 0.2 \mu \mathrm{g} \cdot \mathrm{mL}^{-1}\right)$ was noted at $20 \mathrm{~min}$ in seven patients. In the four other patients, the pharmacokinetic profile was similar to an intravascular injection. The Tmax was unknown because at five minutes the plasma lidocaine concentrations of these four patients were already falling and it is likely that the true peak was missed by not measuring the lidocaine concentration earlier. In these patients the recorded lidocaine concentration at five minutes was $2.6 \pm 0.1 \mu \mathrm{g} \cdot \mathrm{mL}^{-1}$. Pain was mild or absent in the 11 patients. Lidocaine concentrations, obtained at five minutes, in the two patients who developped bradycardia were 2.4 and $2.7 \mu \mathrm{g} \cdot \mathrm{mL}^{-1}$ respectively. No other symptoms related to lidocaine toxicity (headache, numbness, restlessness, blurred vision) were observed. 


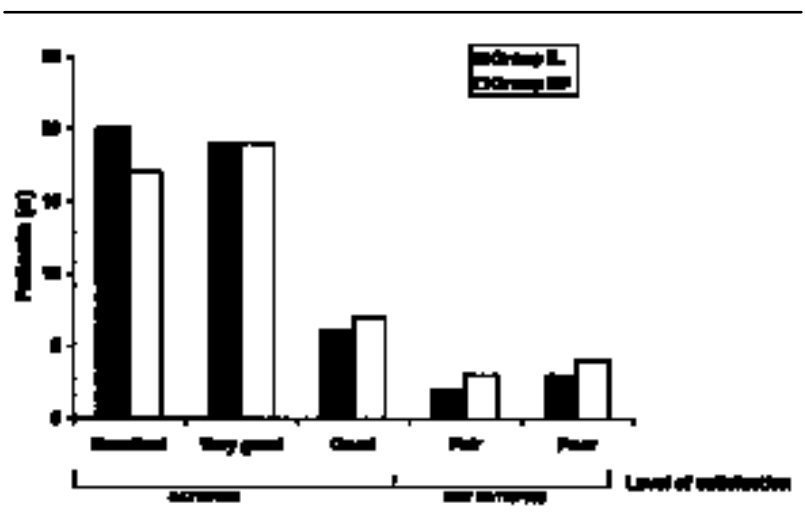

FIGURE 2 Patients' overall satisfaction with the two treatment modalities. No significant difference was observed between the groups. $P=0.9$ intraosseous lidocaine (IL) $v$ nalbuphine and propacetamol $(\mathrm{NP})$.

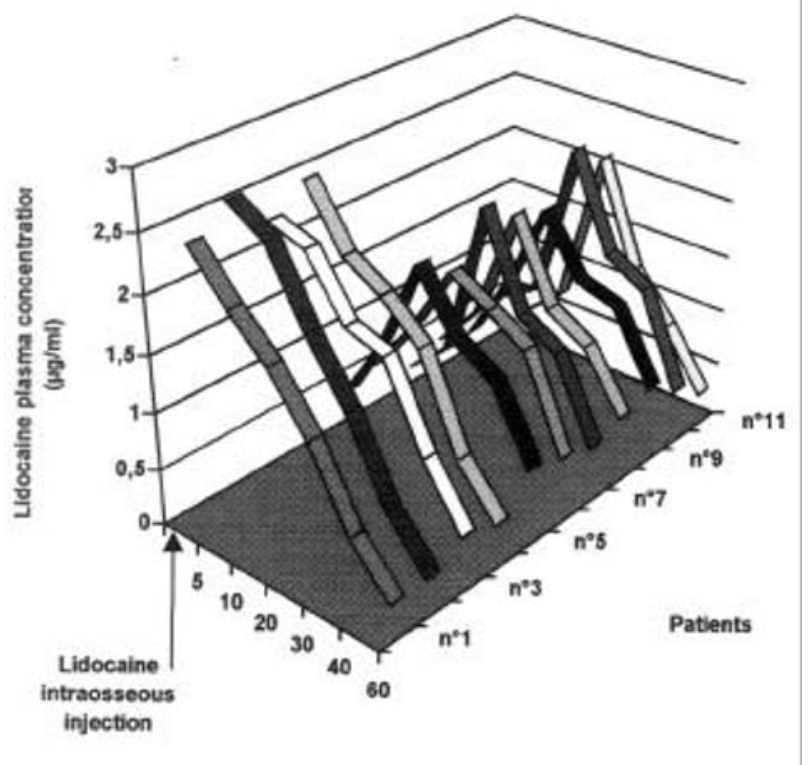

FIGURE 3 Lidocaine plasma concentrations following injection in the osteoporotic vertebral body.

\section{Discussion}

Our study indicates that both IL and iv association of NP are relevant analgesic alternatives to general anesthesia for patients who undergo PV. The protocols were applied only in patients with well documented osteoporotic vertebral compression fractures without malignancy or any other spinal entities. Patients with severe cardiorespiratory, renal and hepatic disease were inten- tionally excluded as they required dose adjustments which would have introduced a bias in our study. The underlying pain mechanisms during vertebroplasty have not been clearly elucidated. Sensitization of neural elements by direct pressure ${ }^{8}$ or by heat generated during cement polymerization ${ }^{9}$ are plausible mechanisms. They produce nociceptive inputs of high intensity and short duration and alternatives to general anesthesia must take this into account.

Our results show that trocar insertion was more painful than cement injection and suggest the need for more effective strategies towards this target. These strategies would imply an understanding of the anatomy of the vertebral body and its interactions with surrounding tissues. Innervation of the vertebral body is provided by the sinu-vertebral nerve, associated with the sympathetic system. ${ }^{10-12}$ It is a highly vascularized zone in which the intraosseous vertebral veins form a freely communicating valveless network with paravertebral and extradural plexus veins. ${ }^{13}$ The rationale of intravertebral injection of lidocaine involves a regional blockade of bone nociceptive inputs. In a recent study, Chandler $e t a l .{ }^{12}$ reported effective pain relief of osteoporotic vertebral fractures by blockade of the gray ramus communicans nerve, a terminal branch of the sinovertebral nerve, which provides sensory input to the disc and vertebral body. However, these authors injected both lidocaine and triamcinolone to produce the nerve block. It is difficult, therefore to dissociate the analgesic effects of each of these drugs. Our study did not precisely determine the mechanism(s) of pain relief during vertebroplasty.

The highest plasma concentration of lidocaine recorded in this study $\left(2.7 \mu \mathrm{g} \cdot \mathrm{mL}^{-1}\right)$ was three-fold below the reported toxic values. ${ }^{14,15}$ In a subgroup of four patients who had a pharmacokinetic profile similar to an intravascular injection, the true peak concentrations were unknown because the first plasma levels obtained at five minutes were already falling. It was difficult for us to obtain reliable blood samples earlier because the study design required a slow and progressive (over two minutes) injection of lidocaine. However, pharmacokinetic studies in critically ill patients and during general anesthesia have shown that $i v$ injection of $1.5 \mathrm{mg} \cdot \mathrm{kg}^{-1}$ or $1 \mathrm{mg} \cdot \mathrm{kg}^{-1}$ of lidocaine produces immediate (within $0.5 \mathrm{~min}$ ) peak plasma concentrations of about $5 \mu \mathrm{g} \cdot \mathrm{mL}^{-1}$ without clinical signs of toxicity. ${ }^{16,17}$ Thus, even if we consider the intraosseous injection as an iv one, the potential risks of such an injection ( $1 \mathrm{mg} \cdot \mathrm{kg}^{-1}$ over two minutes) seems low.

No sympathetic blockade was produced by the intraosseous injection of lidocaine, as demonstrated by the hemodynamic stability in our patients during the 
procedure. This is probably because of the low dose of lidocaine used. However, it is important to distinguish between the hemodynamic variations associated with anesthesia and those associated with methylmethacrylate. A transient decrease in blood pressure and HR is generally observed during the injection of cement. ${ }^{18,19}$ Hypotension has been attributed to vasodilatation as a result of histamine liberation, or to myocardial depression which are supposed consequences of methylmethacrylate toxicity. ${ }^{20}$ More recent studies however, attributed these hemodynamic changes to arterial microemboli which could be visualized by transoesophageal echocardiography. ${ }^{2}{ }^{1}$ Embolization is proportional to intramedullary pressure ${ }^{22}$ and the bone surface involved. ${ }^{2}{ }^{3}$ Compared with hip arthroplasty, the hemodynamic consequences of methylmethacrylate injection are minimized in PV because of the smaller bone surface involved.

Although small quantities of lidocaine and cement are administered, cautious monitoring of neurologic, hemodynamic and respiratory status of each patient is crucial with regard to potential complications. The choice of lidocaine in this study was motivated essentially by its short half-life, ${ }^{14}$ in agreement with the duration of the procedure, and its low intrinsic toxicity compared with other amide local anesthetics. We compared IL anesthesia with iv analgesia associating NP. Nalbuphine, an agonist-antagonist semi-synthetic opioid, was chosen rather than conventional opioids, because of its capacity to exhibit a 'ceiling effect' for respiratory depression. ${ }^{24}$ However, analgesic efficacy is also limited by this 'ceiling effect'. ${ }^{25}$ Therefore, we associated propacetamol to low-dose nalbuphine in order to improve analgesia and reduce side effects. Additionally, propofol sedation was used to prevent unintentional movement in the presence of severe pain. No significant bias in data analysis was introduced as the proportion of severe pain was comparable in the two groups.

Even though perfect analgesia was obtained only in $84 \%$ and $85 \%$ of patients in groups IL and NP respectively, satisfaction levels were high in the two groups. This paradoxical effect may be explained by the rapid improvement in patient comfort after consolidation of the pathologic vertebral body. Therefore overall satisfaction is probably related to both analgesic medication and PV, suggesting that patient satisfaction score is not a very effective means to evaluate a procedure.

The use of VRS instead of the widely accepted visual analog scale for pain assessment is an important limitation of this study because of the incapacity of the VRS to demonstrate small differences in pain relief. Our choice was motivated by its ease of use intraoper- atively, which permitted the assessment of all elderly patients in this particular setting of prone positioning in the radiology suite.

We conclude that IL analgesia is as effective as the $i v$ association of NP for PV of osteoporotic fractures. Lidocaine plasma concentrations measured after intraosseous injection in 11 patients suggest lidocaine toxicity should not be a problem with the doses used in this study (max $125 \mathrm{mg}$ ). However, considering that both protocols still required the addition of propofol in about $10 \%$ of patients, it will be relevant to pursue investigations for more effective analgesic strategies, making general anesthesia unnecessary in these elderly patients.

Acknowledgements

The authors are grateful to Mrs. Valerie Sesay for her linguistic aid; Dr. Brigitte Viaud, Dr.Olivia Delmer, Dr. Jerome Berge, Dr. Jean Pallusiere and the nurse anesthetists of the Department of radiology for their technical assistance.

\section{References}

1 Mathis JM, Barr JD, Belkoff SM, Barr MS, Jensen ME, Deramond H. Percutaneous vertebroplasty: a developing standard of care for vertebral compression fractures. Am J Neuroradiol 2001; 22: 373-81.

2 Jensen ME, Evans AJ, Mathis JM, Kallmes DF, Cloft HJ, Dion JE. Percutaneous polymethylmethacrylate vertebroplasty in the treatment of osteoporotic vertebral body compression fractures: technical aspects. Am J Neuroradiol 1997; 18: 1897-1904.

3 Cotten A, Dewatre F, Cortet B et al. Percutaneous vertebroplasty of osteolytic metastases and myeloma: effects of filling the percentage of lesion and the leakage of methyl methacrylate at clinical follow-up. Radiology 1996: 200: 525-30.

4 Weill A, Chiras J, Simon JM, Rose M, Sola-Martinez T, Enkaoua E.. Spinal metastases: indications for and results of percutaneous injection of acrylic surgical cement. Radiology 1996; 199: 241-7.

5 Orlov GA Intraosseous anaesthesia during plastic operations of the hand and fingers. Acta Chir Plast 1960; 2: 59-63.

6 Waisman M, Roffman M, Bursztein S, Heifetz M Intraosseous regional anesthesia as an alternative to intravenous regional anesthesia. J Trauma 1995; 39: $1153-6$.

7 Keele KD. The pain chart. Lancet 1948; 255: 6-8.

8 Konttinen YT, Grönblad M, Antti-Poika I, et al. Neuroimmunohistochemical analysis of peridiscal nociceptive neural elements. Spine 1990; 15: 383-6.

9 Jefferiss CD, Lee AJC, Ling RSM. Thermal aspects of self-curing polymethylmethacrylate. J Bone Joint Surg 
Br 1975; 57: 511-8.

10 Pedersen HE, Blunck CFJ, Gardner E. The anatomy of lumbosacral posterior rami and meningeal branches of spinal nerves (sinu-vertebral nerves) with an experimental study of their functions. J Bone Joint Surg Am 1956; 38: 377-90.

11 Bogduk N, Long DM. The anatomy of the so-called "articular nerves" and their relationship to facet denervation in the treatment of low-back pain. J Neurosurg 1979; 51: 172-7.

12 Chandler G, Dalley G, Hemmer J Jr, Seely T. Gray ramus communicans nerve block: novel treatment approach for painful osteoporotic vertebral compression fracture. South Med J 2001; 94: 387-93.

13 Gershater R, St. Lowis EL. Lumber epidural venography. Review of 1,200 cases. Radiology 1979; 131: 409-21.

14 Nattel S, Gagne G, Pineau M. The pharmacokinetics of lignocaine and $B$-adrenoceptor antagonists in patients with acute myocardial infarction. Clin Pharmacokinet 1987; 13: 293-316.

15 Moore DC, Crawford RD, Scurlock JE. Severe hypoxia and acidosis following local anesthetic-induced convulsions. Anesthesiology 1980; 53: 259-60.

16 Berkenstadt H, Segal E, Mayan H, et al. The pharmacokinetics of morphine and lidocaine in critically ill patients. Intensive Care Med 1999, 25: 110-2.

17 Kuipers JA, Boer F, de Roode A, Olofsen E, Bovill JG, Burm AGL. Modeling population pharmacokinetics of lidocaine. Should cardiac output be included as a patient factor? Anesthesiology 2001; 94: 566-73.

18 Phillips H, Cole PV, Lettin AWF. Cardiovascular effects of implanted acrylic bone cement. Br Med J 1971; 3: 460-1.

19 Schlag G, Schliep H-J, Dingeldein E, Grieben A, Ringsdorf $W$. Does methylmethacrylate induce cardiovascular complications during alloarthroplastic surgery of the hip joint?(German). Anaesthesist 1976; 25: 60-7.

20 Duncan JAT. Intra-operative collapse or death related to the use of acrylic cement in hip surgery. Anaesthesia 1989; 44: 149-53.

21 Christie J, Burnett R, Potts HR, Pell ACH Echocardiography of transatrial embolism during cemented and uncemented hemiarthroplasty of the hip. J Bone Joint Surg Br 1994; 76-B: 409-12.

22 Orsini EC, Byrick RJ, Mullen JBM, Kay JC, Waddell $J P$. Cardiopulmonary function and pulmonary microemboli during arthroplasty using cemented or non-cemented components. The role of intramedullary pressure. J Bone Joint Surg Am 1987; 69: 822-32.

23 Byrick RJ. Cement implantation syndrome: a time limited embolic phenomenon (Editorial). Can J Anaesth 1997; 44: 107-11.
24 Romagnoli A, Keats AS. Ceiling effect for respiratory depression by nalbuphine. Clin Pharmacol. Ther 1980; 27: 478-85.

25 Gal TJ, DiFazio CA, Moscicki J. Analgesic and respiratory depressant activity of nalbuphine: a comparison with morphine. Anesthesiology 1982; 57: 367-74. 